\title{
Psikolojik Sermayenin Öznel İyi Oluş Üzerindeki Etkisi: İmalat Sektöründe Bir Araştırma
}

\author{
Kemaleddin ERYEŞIL ${ }^{*}$ \\ Aykut BEDÜK**
}

\begin{abstract}
ÖZ
Bu çalışmada, psikolojik sermaye ve öznel iyi oluş kavramları incelenmiş ve bu kavramların ilişkileri incelenerek imalat sektörü çalışanları üzerinde de bir uygulama yapılmıştır. Bu çalışmada, çalışanların psikolojik sermayesinin öznel iyi oluş üzerindeki etkisini analiz etme amacı doğrultusunda Konya'da imalat sektöründe faaliyet gösteren büyük ölçekli işletmelerin çalışanlarından 460 kişiye kolayda örnekleme yoluyla anket yöntemi temel alınarak bir araştırma yapılmıştır. Uygulanan anketlerden eksiksiz doldurulan 439 adedi SPSS programına işlenerek veri seti oluşturulmuştur. Çalışmadan elde edilen veriler Likert ölçeği dikkate alınarak hazırlanan standart bir anket formu aracıllğıyla cevaplayıcılarla yüz yüze yapılan görüşmelerle toplanmıştır. Psikolojik Sermaye Ölçeği olarak Luthans vd. (2007) tarafindan geliştirilen ve Çetin \& Basım (2012) tarafından Türkçe geçerlilik ve güvenilirlik analizleri yapılarak uyarlanan 24 ifade ve 4 boyuttan oluşan psikolojik sermaye ölçeği kullanılmıştır. Öznel İyi Oluş Ölçeği olarak ise Renshaw vd. (2015) tarafından geliştirilen, Ergün \& Nartgün (2017) tarafından Türkçe geçerlilik ve güvenilirlik analizleri yapılan öznel iyi oluş ölçeği kullanılmıştır. Araştırma değişkenlerine güvenirlilik analizi yapılısış, ardından psikolojik sermaye ve öznel iyi oluş arasındaki ilişkiyi incelemek için korelasyon ve çoklu regresyon analizleri yapılarak araştırmanın hipotezi test edilmiştir. Araştırma bulgularına göre, imalat sektörü çalışanlarının psikolojik sermaye ile öznel iyi oluş algıları arasında istatistiksel bakımdan anlamlı $(p<0,05)$ ve pozitif bir ilişki $(r=+0,432)$ olduğu tespit edilmiştir. Benzer şekilde psikolojik sermayenin alt boyutlanı olan umut, öz yeterlilik, iyimserlik ve psikolojik dayanaklılık ile öznel iỷ oluş arasında istatistiksel bakımdan anlamlı ve pozitif bir ilişki olduğu tespit edilmiştir.

Anahtar Kelimeler: Psikolojik Sermaye, Öznel İyi Oluş, Umut, Psikolojik Dayanaklılık, İyimserlik.
\end{abstract}

\section{The Effect of the Psychological Capital on Subjective Well-Being: A Research at Manufacturing Sector}

\begin{abstract}
In this study, psychological capital and subjective well-being concepts and the relationships of these concepts with each other were examined and a field study was conducted on manufacturing sector workers. In the study, in line with the purpose of analysing the effect of employees' psychological capital on subjective well-being. a research has been conducted on 460 employees of large-scale enterprises operating in the manufacturing sector in Konya, based on the survey method through convenience sampling. 439 completely filled ones of the questionnaire forms delivered were entered in the SPSS package and the data set was formed. In the study, the data was collected through face-to-face interviews with the respondent through a standard survey prepared taking into account the Likert scale. Psychological capital scale consisting of 24 expressions and 4 dimensions, which was developed by Luthans et al. (2007) and validated in Turkish by Çetin and Basım (2012), was used as the Psychological Capital Scale. As the subjective well-being scale, subjective well-being scale developed by Renshaw et al. (2015), validity and reliability in Turkish by Ergün and Nartgün (2017) was used. Reliability analysis was performed on the research variables, then the hypothesis of the research was tested by performing correlation and multiple regression analyzes to examine the relationship between them. According to the research findings, it was determined there is a statistically significant $(p<0,05)$ and positive relationship between psychological capital and subjective well-being of manufacturing sector employees. Similarly, a statistically significant and positive relationship $(\mathrm{r}=+0,432)$ was found between subjective well-being and hope, self-efficacy, optimism, and psychological resilience, which are sub-dimensions of psychological capital.
\end{abstract}

Keywords: Psychological Capital, Subjective Well-being, Hope, Psychological Resilience, Optimism.

\section{Giriş}

Genel olarak psikolojik sermaye ekonomi, yatırım ve sosyoloji ile ilgili çalışmalarda yaygın olarak kullanılmıştır. Psikologlar, çalışanların ve kuruluşların hızla değişen teknolojik değişikliklere dayanan iş ortamının zorluklarını kabul etmelerine ve mücadele etmelerine yardımcı olmak için daha olumlu davranışlara ihtiyaç duyulduğunu vurgulamaktadır (Ibrahim vd., 2019, s. 299). İnsan performansına etkisinden dolayı örgütsel davranış literatüründe gittikçe daha fazla ilgi gören bir stratejik kaynak biçimi

\footnotetext{
* Dr. Öğr. Üyesi, Şırnak Üniversitesi, k.eryesil@sirnak.edu.tr

** Prof. Dr., Selçuk Üniversitesi, abeduk@selcuk.edu.tr

Makalenin Gönderim Tarihi: 15.12.2020; Makalenin Kabul Tarihi: 16.04.2021
} 
olan psikolojik sermaye (Ardichvili, 2011), küreselleşmenin ortaya çıkmasıyla birlikte dünyadaki çoğu firmanın yönetiminde giderek daha önemli ve ayrılmaz bir unsur haline gelen bir kavramdır.

Luthans (2002), psikolojik sermayeyi "mevcut işyerinde performansin iyileştirilmesi için ölçülebilen, geliştirilebilen ve yönetilebilen pozitif yönelimli insan kaynağ güçlerini ve etkili psikolojik kapasitenin incelenmesi ve uygulanması" olarak tanımlamaktadır. Psikolojik sermaye "umut, öz yeterlik, dayanıklılık ve iyimserlik" bileşenlerinden oluşmaktadır. Bu bileşenlerin etkileşimi, organizasyondaki çalsşanların motivasyonu ile birlikte yüksek düzeyde etkinlik sağlamaktadır. Psikolojik sermayenin bu dört bileşeni, örgütsel ortamın olumluluk düzeyini artırmada farklı roller oynamakta ve dolayısıyla kurumlardaki verimlilik düzeylerini artırmaya yardımcı olmaktadır. Psikolojik sermayenin bu bileşenleri, özellikle çalışanlar tarafindan benimsenen örgütsel hedeflere yönelik girişimlerin düzeyini artırmakta ve aynı zamanda tüm organizasyon yapısının öngörülen süre içinde firmanın karşılaştı̆̆ hedeflere ulaşılmasına yardımcı olacak bir çerçeve oluşturmasına yardımcı olmaktadır (Lee \& Yang, 2019). Psikolojik sermayeye sahip olmak, bireylerin başarıları ve öznel iyi oluşuyla ilgili olup, psikolojik sermayenin bileşenleri, bireyin davranışlarını belirleyen çok önemli faktörlerdir (Darvishmotevali \& Ali, 2020, s. 3). Öznel iyi oluş, bir bireyin hayatına dair zihinsel ve duygusal yorumlamaları şeklinde ifade edilmektedir. Bu yorumlamalar ise vakalara verilen duygusal tepkilerin yanı sıra doyum/tatminle ilgili zihinsel yargıları içermektedir. $\mathrm{Bu}$ nedenle öznel iyi oluş, hoş duygulan deneyimlemeyi, düşük seviyelerde negatif ruh hallerini ve güçlü yaşam doyumunu içerdiği için pozitif psikolojinin temel kavramlarından biri olarak görülmektedir (Diener vd., 2002, s. 63).

$\mathrm{Bu}$ çalışmada, çalışanların psikolojik sermayesinin öznel iyi oluş üzerindeki etkilerinin incelenmesi amaçlanmaktadır. Bu kapsamda, Konya’da imalat sektöründe faaliyet gösteren büyük ölçekli işletmelerdeki 439 çalışandan elde edilen veriler istatistiksel teknikler ile analiz edilecek ve her iki kavram arasındaki ilişkiler ortaya konulmaya çalışlacaktır.

\section{Kavramsal Çerçeve}

\subsection{Psikolojik Sermaye}

Pozitif örgütsel davranış ilk olarak "günümüz işyerinde performans iyileştirmesi için ölçülebilen, geliştirilebilen ve etkin bir şekilde yönetilebilen pozitif yönelimli insan kaynaklarının güçlü yönleri ile psikolojik kapasitelerinin incelenmesi ve uygulanması" olarak tanımlanmıştır (Luthans, 2002, s. 59). Pozitif örgütsel davranış, işyerinde bireylerin performansının iyileştirilebilmesi için insan kaynaklarının etkinliklerini ve psikolojik kapasitelerini ölçülebilir bir şekilde geliştirmeye odaklanmıştır (Chen vd., 2019, s. 1). Bu nedenle, psikolojik bir güç veya kaynağın pozitif örgütsel davranış anlayışına dahil edilebilmesi için pozitif, ölçülebilir, durumsal veya açı gelişme olması ve istenen tutum, davranış ve özellikle performans sonuçları içermesi gerekmektedir (Luthans vd., 2015, s. 19). Pozitif psikoloji, pozitif örgütsel bilim ve ortaya çıan pozitif örgütsel davranış alanından türetilen teori ve araştırmalara dayanarak Luthans ve arkadaşları "Psikolojik Sermaye" kavramını geliştirmişlerdir (Luthans vd., 2006, s. 387). Psikolojik sermaye, organizasyonlarda performans artışına neden olan insan kaynaklarının potansiyeli ve psikolojik kapasitesi ile ilgili (Çavuş \& Gökçen, 2015, s. 244) ölçülebilen, geliştirilebilen ve kullanılabilecek psikolojik yeteneklerini tespit etmek üzere tasarlanmıştr (Luthans \& Youssef, 2004, s. 152; Newman vd., 2014, s. 120; Nolzen, 2018, s. 236).

Psikolojik sermaye veya pozitif psikoloji olumlu tutumların, geri bildirimlerin, eleştirilerin bir bireyin, grubun veya şirketin işleyişine ve gelişimine katkıda bulunduğu süreçlerin incelenmesi olarak tanımlanmaktadır (Çavuş \& Gökçen, 2015, s. 244). Psikolojik sermaye, işler iyi gittiğinde inşa edilen ve işler kötü gittiğinde kullanılan zihinsel kaynakları kapsamaktadır. Bu kaynaklar, dayanıklılık, motivasyon, umut, iyimserlik, kendine inanç, güven, kendine değer ve enerjiyi içermektedir (Pryce-Jones, 2010, s. 8).

Luthans ve Youssef, (2004)'e göre örgütsel davranışta yer alan öz-yeterlilik, umut, iyimserlik ve dayanıklılık aynı zamanda pozitif psikolojik sermayenin temeli olarak da bilinmektedir. Psikolojik sermaye, "bir bireyin pozitif psikolojik gelişim durumu olarak tanımlanmakta ve şu özelliklerle karakterize edilmektedir: (1) zorlu görevlerde başarılı olmak için gerekli çabayı gösterme ve üstlenme konusunda güvene sahip olmak(öz-yeterlilik); (2) şimdi ve gelecekte başarılı olma konusunda olumlu bir attfta bulunma (iyimserlik); 3) başarıya ulaşmak için hedeflere ulaşmak ve gerektiğinde hedeflere giden yolları yeniden yönlendirmek (umut); ve (4) sorunlar ve güçlüklerle kuşatıldığında, başantya ulaşmak için çabaları 
sürdürüp toparlanmak ve hatta eskisinin ötesine geçmek (dayanıkl1lk)" (Luthans, 2011, s. 219; Chiesa vd., 2018 , s. 2). Ayrıca psikolojik sermaye, insan sermayesinin (yetenekler, bilgi, deneyim ve beceriler) ve sosyal sermayenin (ağlar, ilişkiler) ötesinde başka bir kaynak türü olarak da kabul edilmektedir (Zhen \& Mansor, 2020, s. 592). Bandura'nın sosyal bilişsel teorisine dayanan öz-yeterlilik, bir bireyin yüksek performans seviyelerine ulaşmada motivasyonunu, zihinsel kaynaklarını ve hareket biçimlerini eyleme dönüştürme yeteneklerindeki güvenlerini belirtmektedir (Newman vd., 2014, s. 122). Başka bir ifadeyle öz-yeterlilik, olumlu bir inanc1 temsil etmekte ve kişinin zorlu bir ortamda görevlerde başarılı olmak için gerekli kaynakları ve eylemleri üstlenme ve ortaya koyma güveni olarak tanımlanmaktadır. Öz-yeterliliği yüksek olan insanlar, zorlu görevleri yerine getirme, gerekli bilişsel kaynakları harekete geçirme ve engellerle karş1 karşıya kaldıklarında bile başarılı olma yeteneğine sahiptirler (Nolzen, 2018, s. 240). Umut, önemli amaçların gerçekleştirilmesine dönük inançtır. Başka bir ifadeyle umut, iki önemli unsurun irade (hedefe yönelik enerji) ve yolların (bu hedefleri yerine getirmeyi planlama) birbirleriyle etkileşime girdiği bir motivasyon durumu olarak tanımlanmaktadır (Costa \& Neves, 2017, s. 10). İrade, bireyin belirli bir bağlamda belirli bir görevde başarılı olma motivasyonunu ifade ederken, yollar ise bu görevin gerçekleştirilebileceği yolu veya araçlan ifade etmektedir. Yüksek umut seviyesine sahip insanlar, hedefe yönelik daha yüksek enerji sarf edebilmekte ve hedeflerine ulaşmak için alternatif yollar geliştirme olasılıkları daha yüksek olmaktadır (Newman vd., 2014, s. 122). İyimserlik, gelecek hakkında olumlu beklentilere sahip olma anlamına gelmektedir. Ayrıca iyimserlik, bireyin en iyi olasıllğa ilişkin genel beklentileri ve hedeflerine ulaşmak için ısrar etme potansiyelleri olarak tanımlanmaktadır (Zhen \& Mansor, 2020, s. 592). İyimserlik oranı yüksek olanlar, genellikle onları hedeflerine ulaşmaya ve zor durumlarla başa çıkmaya motive eden olumlu beklentilere sahip olmaktadırlar (Newman vd., 2014, s. 122). Sonuç olarak, iyimserlik insanları olumsuz olaylardan uzaklaştırı olumlu olaylarda kararlılıklarını motive ederken onların zor durumlarla başa çıkmalarına da yardımcı olmaktadır. Sadece içsel bir bakış açısıyla hedeflerin peşinden gitme üzerindeki kişisel eğilimi açılayan öz-yeterlik ve umudun aksine iyimserlik, konuya dişsal bir boyut katmaktadır (Nolzen, 2018, s. 241). Son olarak dayanıklılık, bireyin başarısızlık veya kısıtlı başarı ile karşı karşıya kaldığında geri düşülen noktadan tekrar sıçrama veya toparlanma yeteneğidir (Costa \& Neves, 2017, s. 10). Luthans (2002), dayanıklılı̆̆ "bireyin sıkınt, belirsizlik, çatışma, risk, başarısızlıktan toparlanarak styrılma ve hatta olumlu değişim, ilerleme ve artan sorumluluktan kurtulmak, yeniden yükselmek için pozitif bir psikolojik kapasite" olarak tanımlamaktadır (Ibrahim vd., 2019, s. 299). Dayanıklılı̆̆ yüksek olan çalışanlar, dış ortamdaki olumsuz deneyimler ve değişiklikler karşısında (Newman vd., 2014, s. 122), gerçeği kabul etme, yeni durumlara cevap verme ve uyum sağlama kabiliyetine sahip olan istikrarlı bir inanç setine sahip olmaktadırlar (Nolzen, 2018, s. 241). Psikolojik sermayenin bu bileşenleri, bir bireyin davranışlarını belirleyen çok önemli faktörlerdir (Darvishmotevali \& Ali, 2020, s. 3). Psikolojik sermaye, bireylerin hem duygusal hem de bilişsel olan yaşamları hakkındaki değerlendirmelerini ifade öznel iyi oluşlarını da etkilemektedir (Margıtıcs \& Pauwlık, 2009, s. 84).

\section{2. Öznel İyi Oluş}

Eski zamanlardan beri insanlar, iyi bir hayatı anlamlı kılan şeyleri merak etmişlerdir. Öznel iyi oluşu inceleyen bilim insanlanı, iyi yaşamın temel bileşenlerinden birinin, kişinin kendi hayatını sevmesi olduğunu varsaymaktadırlar. Öznel iyi oluş, bireyin hayatına ilişkin hem zihinsel hem de duygusal yorumlamaları şeklinde ifade edilmektedir. Bu yorumlamalar, olaylara verilen duygusal tepkilerle birlikte doyum ve tatminle ilgili zihinsel yargıları içermektedir (Diener, 2000, s. 34). Bu nedenle öznel iyi oluş, hoş duyguları deneyimlemeyi, düşük seviyelerde negatif ruh hallerini ve güçlü yaşam doyumunu içermesinden ve yaşamı ödüllendirmesinden dolayı pozitif psikolojinin temel kavramlanndan biridir (Diener vd., 2002, s. 63).

Öznel iyi oluş, pozitif psikoloji alanının bir türevi olup, bireylerin optimal işleyişini ve deneyimini sağlamak için olumlu duyguların geliştirilmesini gerektirmektedir (Hansen vd., 2015: 3). Öznel iyi oluş, çeşitli boyutlardan oluşan kapsayıcı bir yapı olarak kavramsallaştırılmıştır. Öznel iyi oluş çok yönlü olmakla birlikte "kişinin yaşamının bilişsel bir değerlendirmesi", "düşük ancak uygun düzeyde olumsuz duygu" ve "kişinin olumlu duygularının duygusal değerlendirmesi" şeklinde bireylerin yaşamlarının en az üç bileşenine ilişskin değerlendirmelerini kapsamaktadır (Margıtıcs \& Pauwlık, 2009, s. 84). İlk bileşen, bir kişinin geçmiş, şimdiki ve gelecekteki beklentilerinin bilişsel bir değerlendirmesini içermekte ve bunlarnn tümü bir kişinin 
yaşamından genel memnuniyet derecesine katkıda bulunabilmektedir. İkinci bileşen, iyi oluşun düşük fakat uygun seviyelerde olumsuz duygulanımdan oluştuğunu vurgulamaktadır. Başka bir deyişle, pozitif psikoloji alanında çalışanlar genellikle olumsuz etkilerin tümünün ortadan kaldırılmasını olmazsa olmaz bir koşul olarak ele almadıkları gibi bu ortadan kaldırmanın mutlak bir faydası olduğunu da ileri sürmemektedirler. Üzüntü, pişmanlık, suçluluk ve depresyon gibi olumsuz duygular pozitif psikoloji alanında çalışanlar için önemli ve değerlidir. Üçüncü bileşen ise duygusal değerlendirmeyi içermekte olup genellikle daha güncel bir odağa sahiptir. Bir kişinin şimdiki veya anlık mutluluk durumu ve genel mutluluk durumu dahil olmak üzere hayatını çevreleyen duygusal bileşenler hakkında nasıl hissettiğini içermektedir (Holder, 2012, s. 1).

Öznel iyi oluş, insanların yaşamlarına ilişkin sübjektif yorumlamalarına ilişkin yaşadıkları mutluluk düzeyini tanımlamada kullanılan genel bir kavramdır. Hem negatif hem de pozitif olabilen bu yorumlamalar, yaşam tatmini, ilgi, bağılıı hakkındaki yargılanı, duygulanı, yaşam olaylarına neşe ve keder benzeri duygusal tepkilerle, çalş̧ma, temaslar, sthhat, eğlence, mana ve amaçtan duyulan memnuniyeti ve diğer önemli alanları içermektedir. Ancak, iyi oluş bireyin deneyiminde meydana gelmesi açısından sübjektif olduğu halde, öznel iyi oluşun belirtilerinin sözlü ve sözlü olmayan davranışlarda, eylemlerde, biyolojik verilerde, dikkatte ve bellekte nesnel olarak ölçülebileceğini belirtmek önemlidir (Diener \& Ryan, 2009, s. 391).

Öznel iyi oluş, insanların yaşamları hakkındaki hem duygusal hem de bilişsel değerlendirmelerini ifade etmektedir (Diener, 2000, s. 34). Genel olarak öznel iyi oluş kavramının bilişsel değerlendirme ve duygusal değerlendirme olmak üzere iki geniş unsuru içerdiği konusunda bir fikir birliği söz konusudur. Genel yaşam memnuniyetinin ve belirli alanlardaki memnuniyetin (aile hayatı, kariyer vb.) nasıl derecesini açıklayan bilişsel değerlendirmedir. Başka bir ifadeyle bilişsel değerlendirme, bireylerin genel olarak yaşam doyumu (bir bütün olarak yaşam) ve aynı zamanda belirli bir yaşam alanında (iş, ilişkiler, vb.) yaşam doyumları hakkında ne düşündüklerini ifade etmektedir (Darvishmotevali \& Ali, 2020, s. 3). Duygusal değerlendirme ise duygusal deneyimlerimizle ilgilidir. Yüksek düzeyde öznel iyi oluş, sık ve yoğun olumlu durumların (sevinç, umut ve gurur) ve olumsuz durumların genel yokluğunun (öfke, kıskançlık ve hayal kırıklığı) deneyimidir (Moore, 2020). Başka bir ifadeyle, insanlar çok hoş ve az hoş olmayan duygular hissettiklerinde, ilginç faaliyetlerde bulunduklanında, çok fazla zevk ve az acı yaşadıklarında ve yaşamlarından memnun olduklarında yüksek düzeyde öznel iyi oluş yaşamaktadırlar (Diener, 2000, s. 34).

Öznel iyi oluşun temel amacı, derin olumsuzlukların ortadan kaldırılmasından ziyade bireylerin hayatlarının daha sağlıklı hale getirilmesidir. Öznel iyi oluşun ölçülmesi, yaşam kalitesinin hayati bir unsuru olmasından dolayı insanların yaşamlarını ne şekilde iyileştirebileceğinin anlaşılması açısından oldukça elzemdir. Buna ilaveten, yapılan çalışmalarda, yüksek oranda öznel iyi oluşun kişilere sağladığı yararlardan ziyade toplumların etkili ve verimli işlemesine yaptığı katkılara dikkat çekilmektedir (Diener \& Ryan, 2009, s. 392).

Daha fazla öznel iyi oluşa sahip kişiler, birçok yaşam alanında daha başarılıdır ve başarıları en azından kısmen daha yüksek iyi oluş duygusundan kaynaklanmaktadır (Maddux, 2018). Öznel iyi oluşa sahip kişiler, daha sosyal, fedakâr ve aktifler; kendilerini ve diğer insanları daha çok severler, daha güçlü vücutlara ve bağışıklık sistemlerine ve daha iyi çatışma çözme becerilerine sahiptirler ve yaratıcı düşünmeyi teşvik etmektedirler (Lyubomirsky vd., 2005; Eid \& Larsen, 2008; Maddux, 2018).

\subsection{Psikolojik Sermayenin Öznel İyi Oluş Üzerindeki Etkisi}

Örgütsel davranış yazınında psikolojik sermayeyle öznel iyi oluş arasında bir ilişkinin varlı̆̆ını gösteren çok az doğrudan kanıt üretilmesine rağmen araştırmacılar, psikolojik sermayenin öznel iyi oluş üzerinde olumlu bir etkisi olabileceğini öne sürmektedirler. Öznel iyi oluş, pozitif psikoloji alanının önemli kavramlarından biri olarak bireylerin optimal işleyişini ve deneyimini sağlamak için olumlu duyguların geliştirilmesini ifade etmekte, bu nedenle yüksek düzeyde psikolojik sermaye düzeyine sahip bireylerin, eylemlerinde başarılı olma şanslarının daha yüksek olduğu ve dolayısıyla öznel iyi oluş düzeylerinin de yüksek olduğu belirtilmektedir (Li vd., 2014; Afzal vd., 2014; Çetin vd., 2015; Singhal vd., 2018; Ilgaz \& Sayar, 2020; Bolelli, 2020). Psikolojik sermaye ve öznel iyi oluş araşturmalarıyla ilgili ayrı ayrı farklı değişkenlerle çok fazla sayıda araştırma yapılmış olmasına rağmen özellikle Türkçe yazında çok az sayıda 
çalışmaya rastlanması bu çalışmanın önemini artırdığ1 ve çalışmanın bu yönüyle örgütsel davranış alanındaki Türkçe literatüre katkı sağlayacağı düşünülmektedir.

Yüksek psikolojik sermaye gibi daha pozitif psikolojik kaynaklara sahip kişiler daha yüksek bir öznel iyi oluş seviyesine sahip olması beklenebilir (Li vd., 2014, s. 136). Ayrıca, yüksek düzeyde psikolojik sermayeye sahip bireylerin, eylemlerinde başarılı olma şanslarının daha yüksek olduğu ve bunun da onlara bir doyum veya tatmin duygusu kazanmalarına ve dolayısıyla öznel iyi oluşlarını artırmalarına yardımcı olabileceği belirtilmektedir (Afzal vd., 2014).

Bu doğrultuda bu çalışmanın amacı Konya ilinde imalat sektöründeki çalışanların psikolojik sermayeyle öznel iyi oluş düzeyleri arasındaki ilintiyi tespit etmektir. Araştırma kapsamında ele alınan değisskenlere ilişkin araştırma hipotezi aşağıda belirtilmiştir:

Hipotez 1: "Çalışanların psikolojik sermaye düzeyleri ile öznel iyi oluşları arasında pozitif yönlü ilişki vardır."

\section{Araştırma Metodolojisi}

Çalışmanın veri setinin oluşturulmasında anket yönteminden yararlanılmış olup araştırma Konya ilinde imalat sektöründe faaliyet gösteren büyük ölçekli işletmelerdeki çalışanlar üzerinde yürütülmüştür. Çalısmada veriler Likert ölçeği dikkate alınarak hazırlanan standart bir anket formu aracilığıyla cevaplayıcılarla yüz yüze yapılan görüşmelerle toplanmıştır. Araştırmada örnekleme dahil edilecek çalışanlarnn belirlenmesinde benzer çalışmalarda kullanılan kolayda örnekleme yöntemi tercih edilmiştir. Örnek büyüklügünün hesaplanmasında Yazıcıoğlu ve Erdoğan (2004, s. 50)'dan yararlanılmıştr. Araştırma evreni olarak seçilen Konya ilinde imalat sektöründe çalışan 439 çalışan üzerinde görgül bir araştırma yapılmıştır. Araştırmanın verileri Mayıs-Ağustos 2019 tarihleri arasında toplanmıştır. Araştırmaya katılan çalışanların büyük bir kısmının erkek (\%74), 30-40 yaş arası (\%55), lise mezunu (\%65) olduğu ve 5 yıldan uzun süredir (\%64) imalat sektöründe çalıştıkları tespit edilmiştir.

- Psikolojik Sermaye Ölçeği: Luthans vd. (2007) tarafindan geliştirilen ve Çetin \& Basım (2012) tarafindan Türkçe geçerlilik ve güvenilirlik analizi yapılan 24 ifade ve 4 boyuttan oluşan psikolojik sermaye ölçeği kullanılmıştır.

- Öznel İyi Oluş Ölçeği: Renshaw vd. (2015) tarafindan geliştirilen ve Ergün \& Nartgün (2017) tarafından Türkçe geçerlilik ve güvenilirlik analizi yapılarak dilimize uyarlanan öznel iyi oluş ölçeği kullanılmıştır.

Tablo 1. Öznel İyi Oluş Ölçeğinin Geçerlilik ve Güvenilirlik Analizi

\begin{tabular}{|l|c|}
\hline Faktör/Madde & Faktör Yükleri \\
\hline Kendimi bu kuruma ait hissediyorum. & 0,592 \\
\hline Başarılı bir çalışanım. & 0,714 \\
\hline Bu kurumda gerçekten kendim olabilirim. & 0,675 \\
\hline Astlarımın yeni şeyler öğrenmesine yardım etmede iyiyim. & 0,713 \\
\hline Bu kurumdaki insanların beni önemsediklerini hissediyorum. & 0,656 \\
\hline Bir çalışan olarak pek çok şey başardım. & 0,633 \\
\hline Bu kurumda saygı görüyorum. & 0,619 \\
\hline Mesleğimin etkili ve yararlı olduğunu hissediyorum. & 0,622 \\
\hline Toplam Açıklanan Varyans (\%) & 74,558 \\
\hline KMO & 0,836 \\
\hline Barlett Uygunluk Testi & 2067,923 \\
\hline Cronbach Alpha & 0,820 \\
\hline
\end{tabular}

Direct Oblimin yöntemi kullanılarak gerçekleștirilen asal bileșen analizi sonucunda öznel iyi oluş ile ilgili oluşan tek faktörlü yap1 varyansın \%74,558'ini açıklamaktadır. Özdeğerleri 1'den büyük olan maddelerin faktör yükleri 0,5'den büyüktür (Yaşlığlu, 2017). Öznel iyi oluş ölçeğinin geçerlilik analizi için yapılan açıklayıcı faktör analizi sonucunda, Barlett normal dağılım test sonucunun anlamlı ve güvenilir olduğu sonucuna ulaşılmıştır $(\mathrm{p}<0.01)$. Açılayıcı faktör analizi kapsamında öznel iyi oluş ölçeğine ilişkin elde edilen yapının ise Ergün \& Nartgün (2017) tarafindan ileri sürülen yap1 ile uyumlu olduğu 
görülmektedir. Ayrıca öznel iyi oluş ölçeğinin yüksek derecede $(0,60>\alpha>0,80)$ güvenilir olduğu sonucuna ulaşılmıştır.

Tablo 2. Psikolojik Sermaye Ölçeğinin Geçerlilik ve Güvenilirlik Analizi

\begin{tabular}{|c|c|c|c|c|}
\hline Faktör/Madde & $\begin{array}{c}\mathrm{O} z \\
\text { Yeterlilik }\end{array}$ & $\begin{array}{c}\text { Psikolojik } \\
\text { Dayanılklı1ı }\end{array}$ & Umut & İyimserlik \\
\hline Bir grup iş arkadaşıma bir bilgi sunarken kendime güvenirim. & 0,793 & & & \\
\hline Çalışma alanımda, hedefler/amaçlar belirlemede kendime güvenirim. & 0,527 & & & \\
\hline $\begin{array}{l}\text { Yönetimin katıldığı toplantılarda kendi çalışma alanımı açıklarken kendime } \\
\text { güvenirim. }\end{array}$ & 0,783 & & & \\
\hline Uzun dönemli bir probleme çözüm bulmaya çalışırken kendime güvenirim. & 0,818 & & & \\
\hline $\begin{array}{l}\text { Organizasyonun stratejisi konusundaki tartışmalara katkıda bulunmada } \\
\text { kendime güvenirim. }\end{array}$ & 0,601 & & & \\
\hline $\begin{array}{l}\text { Organizasyon dışındaki kişilerle (tedarikçiler, tüketiciler vb.) problemleri } \\
\text { tartışmak için temas kurarken kendime güvenirim. }\end{array}$ & 0,724 & & & \\
\hline $\begin{array}{l}\text { Daha önceleri zorluklar yaşadığım için, işimdeki zor zamanların üstesinden } \\
\text { gelebilirim. }\end{array}$ & & 0,546 & & \\
\hline Genellikle, ișimdeki stresli șeyleri sakin bir șekilde hallederim. & & 0,806 & & \\
\hline Eğer zorunda kalırsam, işimde kendi bașıma yeterim. & & 0,516 & & \\
\hline İșimde birçok şeyleri halledebileceğimi hissediyorum. & & 0,537 & & \\
\hline İşimdeki zorlukları genellikle bir şekilde hallederim. & & 0,799 & & \\
\hline Bu aralar kendim için belirlediğim iş amaçlarımı yerine getiriyorum. & & & 0,805 & \\
\hline Herhangi bir problemin çözümü için birçok yol vardır. & & & 0,736 & \\
\hline $\begin{array}{l}\text { Eğer çalışırken kendimi bir tıkanıklık içinde bulursam, bundan kurtulmak } \\
\text { için birçok yol düşünebilirim. }\end{array}$ & & & 0,822 & \\
\hline Şu anda, işimde kendimi çok başarılı olarak görüyorum. & & & 0,841 & \\
\hline Șu anda iș amaçlarımı sıkı bir șekilde takip ediyorum. & & & 0,791 & \\
\hline Mevcut iş amaçlarıma ulaşmak için birçok yol düşünebilirim. & & & 0,781 & \\
\hline İşimde benim için belirsizlikler olduğunda, her zaman en iyisini isterim. & & & & 0,767 \\
\hline İşimle ilgili şeylerin daima iyi tarafinı görürüm. & & & & 0,854 \\
\hline İşimle ilgili gelecekte başıma ne geleceği konusunda iyimserimdir. & & & & 0,853 \\
\hline İşime "her şeyde bir hayır vardır" şeklinde yaklaşıyorum. & & & & 0,803 \\
\hline Açıklanan Varyans & 20,167 & 16,104 & 19,36 & 10,212 \\
\hline Toplam Aç1klanan Varyans (\%) & & & & 63,844 \\
\hline KMO & & & & 0,764 \\
\hline Barlett Uygunluk Testi & & & & 1570,212 \\
\hline Cronbach Alpha & & & & 0,729 \\
\hline
\end{tabular}

Direct Oblimin yöntemi kullanılarak gerçekleştirilen asal bileşen analizi sonucunda psikolojik sermaye ölçeği ile ilgili oluşan dört faktörlü yapı varyansın \%63,844'ünü açıklamaktadır. Özdeğerleri 1'den büyük olan maddelerin faktör yükleri 0,5'den büyüktür (Yaşlıŏglu, 2017). Psikolojik sermaye ölçeğinin geçerlilik analizi için yapılan açıklayıcı faktör analizi sonucunda, Barlett normal dağılım test sonucunun anlamlı ve güvenilir olduğu sonucuna ulaşılmıştır ( $<<0.01)$. Açıklayıcı faktör analizi kapsamında psikolojik sermaye ölçeğine ilişkin elde edilen yapının Çetin \& Basım (2012) tarafından ileri sürülen yapı ile uyumlu olduğu ve ölçeğin 4 boyutta ele alınabileceği tespit edilmiştir. Ayrıca ölçeğinin yüksek derecede $(0,60>\alpha>0,80)$ güvenilir olduğu sonucuna ulaşılmıştır. Araştırmada kullanılan ölçeklerin ortalama, standart sapma ve korelasyon değerleri aşağıda Tablo 3'de yer almaktadır.

Tablo 3. Değişkenlere Ait Ortalama, Standart Sapma, Güvenilirlik ve Korelasyon Değerleri

\begin{tabular}{|l|l|l|l|l|l|l|l|l|}
\hline Değişkenler & $\mathbf{X}$ & SD & $\mathbf{1}$ & $\mathbf{2}$ & $\mathbf{3}$ & $\mathbf{4}$ & $\mathbf{5}$ & $\mathbf{6}$ \\
\hline Umut & 3,68 & 0,73 & 1 & & & & & \\
\hline İyimserlik & 3,48 & 0,76 &, $457^{* *}$ & 1 & & & & \\
\hline Öz Yeterlilik & 3,46 & 0,74 &, $166^{* *}$ &, $303^{* *}$ & 1 & & & \\
\hline Psikolojik Dayanıklılık & 3,38 & 0,8 &, $181^{* *}$ &, $313^{* *}$ &, $435^{* *}$ & 1 & & \\
\hline Psikolojik Sermaye & 3,5 & 0,53 &, $595^{* *}$ &, $777^{* *}$ &, $723^{* *}$ &, $667^{* *}$ & 1 & \\
\hline Öznel İyi Oluş & 3,33 & 0,65 &, $276^{* *}$ &, $461^{* *}$ &, $188^{* *}$ &, $264^{* *}$ &, $432^{* *}$ & 1 \\
\hline
\end{tabular}


Araştırma değişkenlerine ait tanımlayıcı istatistikler değerlendirildiğinde, psikolojik sermayenin alt boyutlar1 olan umut (Ort. $=3,68$; S.S. $=0,73)$, iyimserlik (Ort. $=3,48$; S.S. $=0,76)$, öz yeterlilik $($ Ort. $=3,46$; S.S. $=0,74)$, psikolojik dayanıkl11k $($ Ort. $=3,38 ;$ S.S. $=0,80)$ ve psikolojik sermaye düzeylerinin $($ Ort. $=3,50$; S.S. $=0,53)$ orta düzeyde olduğu gözlemlenmektedir. Çalş̧anların öznel iyi oluş düzeylerinin de (Ort. $=3,33$; S.S. $=0,65)$ orta düzeyde olduğu ifade edilebilmektedir. Ayrıca araştırma değişkenlerine ilişkin pearson korelasyon analizi sonuçları incelendiğinde, umut ve öznel iyi oluş arasında düşük düzeyde ve pozitif yönlü $(\mathrm{r}=0,276, \mathrm{p}<0,001)$, iyimserlik ve öznel iyi oluş arasında orta düzeyde $(\mathrm{r}=0,461, \mathrm{p}<0,001)$ pozitif yönlü ve istatistiksel bakımdan anlamlı bir ilişki olduğu sonucuna ulaşılmıştı. Psikolojik sermayenin öz yeterlilik boyutu ile öznel iyi oluş arasında düşük düzeyde $(r=0,188, p<0,001)$ pozitif yönlü ve istatistiksel bakımdan anlamlı bir ilişki, psikolojik dayanıklılık ile öznel iyi oluş arasında düşük düzeyde $(r=0,264, p<0,001)$ pozitif yönlü ve istatistiksel bakımdan anlamlı bir ilişki ve psikolojik sermaye ile öznel iyi oluş arasında orta düzeyde $(\mathrm{r}=0,432, \mathrm{p}<0,001)$ pozitif yönlü ve istatistiksel bakımdan anlamlı bir ilişki olduğu tespit edilmiştir. Araştırmada ileri sürülen hipotezleri test etmek amacıyla yapılan regresyon analizi Tablo 4'de yer almaktadır.

Tablo 4. Regresyon Analizi Sonuçları

\begin{tabular}{|c|c|c|c|c|c|c|c|c|}
\hline Bağ1mlı Değişken & $\mathbf{R}^{2}$ & Bağımsız Değişkenler & B & Std. Hata & Beta & $\mathbf{t}$ & $p$ & $\mathbf{F}$ \\
\hline \multirow{5}{*}{ Öznel İyi Oluş } & \multirow{5}{*}{.233} & Sabit & 1,59 & 0,134 & & 11,838 & 0 & \multirow{5}{*}{63.267} \\
\hline & & Umut & 0,068 & 0,03 & 0,076 & 2,236 & 0,026 & \\
\hline & & İyimserlik & 0,325 & 0,03 & 0,384 & 10,717 & 0 & \\
\hline & & Öz Yeterlilik & 0,003 & 0,03 & 0,003 & 0,084 & 0,933 & \\
\hline & & Psikolojik Dayanıklılık & 0,104 & 0,028 & 0,129 & 3,745 & 0 & \\
\hline
\end{tabular}

Regresyon analizi sonuçları incelendiğinde, açılayıcı değişken olan psikolojik sermayenin alt boyutları olan umut, iyimserlik, öz yeterlilik ve psikolojik dayanıklılığın bağımlı değişken olan öznel iyi oluşu anlamlı bir şekilde yordadığı ve değişimin \%23,3’ünü açıkladığ1 tespit edilmiştir $(\mathrm{p}<0,05)$. Analiz sonuçları değerlendirildiğinde, psikolojik sermayenin alt boyutlannda iyimserlik ve psikolojik dayanıkl1lı̆̆n öznel iyi oluş üstünde en fazla etkiye sahip olduğu tespit edilmiştir. Bununla birlikte psikolojik sermayenin öz yeterlilik boyutunun çalışanların öznel iyi oluş düzeyleri üzerinde anlamlı bir etkisi bulunmadığı sonucuna ulaşılmıştır $(p>0,05)$. Analiz sonuçları dikkate alındığında araştırmanın ileri sürülen hipotezi kısmen desteklenmektedir.

\section{Sonuç}

$\mathrm{Bu}$ çalş̧manın amacı psikolojik sermayenin öznel iyi oluş arasındaki ilişkinin incelenmesidir. Örgütsel davranış yazınında psikolojik sermaye ile öznel iyi oluş arasında pozitif yönlü bir ilişsi olduğu belirtilmektedir (Li vd., 2014; Afzal vd., 2014; Çetin vd., 2015; Singhal vd., 2018; Gupta \& Shukla, 2018; Ilgaz \& Sayar, 2020; Bolelli, 2020). Mevcut çalışmada elde edilen sonuç, psikolojik sermayenin alt boyutları olan umut, iyimserlik, öz yeterlilik ve psikolojik dayanakllık ile öznel iyi oluş arasında da pozitif yönlü ve istatistiksel bakımdan anlamlı bir etkisinin olduğu sonucuna ulaşılmıştır. Ayrıca, iyimserlik ve psikolojik dayanıklılık boyutunun öznel iyi oluş üzerinde en fazla etkiye sahip olduğu sonucuna ulaşılmıştır. Benzer şekilde, psikolojik sermayenin öznel iyi oluş üzerinde pozitif yönlü ve istatistiksel bakımdan anlamlı bir etkisinin olduğu sonucuna ulaşılmışıı. Bahsedilen ilişki psikolojik sermaye algısı yüksek olan bireylerin yüksek düzeyde öznel iyi oluş algısına sahip olduklarını göstermektedir. Bununla birlikte, psikolojik sermayenin çalışanların öznel iyi oluşunu geliştirmek için kullanılan olumlu bir kaynak olabileceğine dair ön kanıt sağlamaktadır. Ancak öznel iyi oluş, katılımcının kendi deneyimlerine ve bakış açılarına temel vurgu yaptığından, insanlar mutluluk yaşasalar bile eksiksiz bir psikolojik iyi oluştan bahsetmek için daha derin analizlere ihtiyaç bulunmaktadır. Bununla birlikte, psikolojik sermayenin öznel iyi oluş arasındaki ilisskiyi inceleyen sınırlı sayıda çalışmanın olması nedeniyle bu araştırmanın örgütsel davranış yazınına katkı sağlayacağ1 düşünülmektedir.

Gelecekte psikolojik sermaye ve öznel iyi oluş değişkenlerinin farklı değişkenlerle özellikle aracıllk etkisini ölçecek şekilde ve farklı sektör çalışanlarıyla daha geniş örneklemlerle araştırma konusu olarak ele alınabilir. Mevcut araştırma, Konya ilindeki imalat sektörünün çalışanlarıyla sınırlıdır. Farklı 
şehirlerde/örneklerde veya kamu çalışanlarıyla daha ileri çalışmalar yapilabilir. Ayrıca mevcut araştırma, araşırma soruları ve hipotezler niteliği alınarak belirli zaman sınırlamaları içinde yürütüldüğünden, veri toplama açısından daha uzun sürelerde ileri çalışmalar yapilabilmektedir

\section{Extended Abstract}

Psychological capital has quite often been used in studies related to economics, investment and sociology. Psychologists have noted that more positive behaviours are needed in order to help employees and organizations embrace and struggle against the challenges of the workplace caused by technological advancements (Ibrahim et al., 2019, p. 299). Psychological capital is a type of strategic resource that has drawn increasing attention in the organizational behaviour literature due to its effect on the human performance (Ardichvili, 2011). Psychological capital has become more a more significant and indispensable element in the management of many firms worldwide together with the emergence of globalization.

Luthans (2002) defines psychological capital as "examining and applying positive human resources and effective psychological capacity which can be measured, improved and managed in order to increase performance in the workplace". There are several components that are involved in the structure of psychological capital as a whole. The interaction of these components which are hope, self-efficacy, resilience and optimism results in high efficiency together with employees' motivation. The four components of psychological capital play different roles in increasing the level of positivity and help increase the level of efficiency in different organizations. These components aim to increase the attempts intended to achieve the employees' purposes and help create a framework that will enable the firm to accomplish organizational aims in the predicted time period (Lee and Yang, 2019). These components are also very important factors that determine the behaviours of an individual. having psychological capital is related to an individual's success and subjective well-being (Darvishmotevali and Ali, 2020, p. 3).

Subjective well-being is defined as an individual's cognitive and affective interpretations of his/her life. These interpretations include the mental judgments about satisfaction as well as the reactions given to phenomena. Therefore, subjective well-being is considered as one of the fundamental concepts of positive psychology since it involves experiencing pleasant feelings, low levels of negative state of mind and a more powerful life satisfaction (Diener et al., 2002, p. 63).

Subjective well-being is a sub-category of positive psychology field and it requires developing positive feelings in order to ensure optimal functioning of individuals (Hansen et al., 2015: 3). Subjective wellbeing has been conceptualized as an inclusive construct comprising of various dimensions. Subjective well-being includes evaluations of at least three components of individuals' lives which are "a cognitive evaluation of a person's life", "low but appropriate level of negative feelings" and "affective evaluation of a person's positive feelings" (Margitics \& Pauwlik, 2009, p. 84). The first component involves a cognitive evaluation of a person's past, present and future expectations and all of these contribute to the general satisfaction level of a person regarding his/her life. The second component points out the fact that wellbeing consists of low but appropriate level of negative feelings. In other words, positive psychologists generally are not concerned with the elimination of all negative effects and they do not consider this elimination to be necessarily beneficial. Knowing the value of negative emotions such as sadness, regret, guilt and depression is important for positive psychologists. The third component includes affective evaluation and it is often focused on what's contemporary. It refers to how a person feels about affective factors surrounding his/her life, including their current and general state of happiness (Holder, 2012, p. 1).

Although there are very few direct evidences showing the link between psychological capital and subjective well-being, researchers put forward that psychological capital could have a positive impact on subjective well-being. Therefore, the purpose of this study is to find out the relationship between the psychological capital and subjective well-being levels of the employees working in manufacturing sector in Konya province. Accordingly, a survey was conducted through questionnaire method on the employees of large-scale businesses operating in manufacturing sector in Konya province by convenience sampling. In the study, data was collected by face-to-face interviews with participants through a standard questionnaire form prepared based on Likert scale. The psychological capital scale developed by Luthans et al. (2007) 
and validated in Turkish language by Çetin and Basım (2012) consisting of 24 items and 4 dimensions was used in order to measure psychological capital. The subjective well-being scale developed by Renshaw et al. (2015) and validated in Turkish by Ergün and Nartgün (2017) was used in order to measure subjective well-being. Convenience sampling method which has been used in similar previous studies was preferred in order to determine the participants of the study. The study by Yazıcıŏllu and Erdoğan (2004:50) was referred to in the calculation of sample size. An empirical study was carried out on the 439 employees working in the manufacturing sector in Konya province, which is the research population. The data of the study was collected between May-August 2019. It was found out that the majority of the research participants are male (74\%), aged between 30-40 (55\%) and high school graduates (65\%) and have been working in the manufacturing sector for over 5 years $(64 \%)$.

It is indicated in the organizational behaviour literature that there is a positive relationship between psychological capital and subjective well-being (Li et al., 2014; Afzal et al., 2014; Çetin et al., 2015; Singhal et al., 2018; Gupta and Shukla, 2018; Ilgaz and Sayar, 2020; Bolelli, 2020). The results obtained in this study suggest that there is a positive and statistically meaningful relationship between hope, optimism, self-efficacy and psychological resilience, which are sub-dimensions of psychological capital, and subjective well-being. Furthermore, it was revealed that optimism and psychological resilience have the highest level of impact on subjective well-being. Similarly, it was found out that psychological capital has a positive and statistically meaningful effect on subjective well-being. These results explain the reason for individuals with high perception of psychological capital also having high level of subjective well-being. Yet, it can be considered as a potential evidence that psychological capital can be a positive resource that can be used to develop employees' subjective well-being. However, as subjective well-being emphasizes the participants' own experiences and points of view, and as people can still have psychological disorders despite being happy, it does not supply a full understanding of people's mental health. Therefore, it is recommended that different variables apart from subjective well-being should be used in evaluating a person's psychological health. The fact that there are a limited number of studies examining the relationship between psychological capital and subjective well-being increases the quality of the study and enables the study to contribute to the organizational behaviour literature.

Future studies can measure the mediating role of psychological capital and subjective well-being with various variables and further research can be performed with employees from different sectors with bigger samples. This study is limited to the employees in the manufacturing sector in Konya. Further studies can be conducted in different cities/samples or with civil servants. Besides, this study was carried out under certain time limitations considering the research questions and the research hypotheses. Further studies can be conducted in long periods of time.

\section{Kaynakça}

Afzal, A., Malik, N. I., \& Atta, M. (2014). The Moderating Role of Positive and Negative Emotions in Relationship Between Positive Psychological Capital and Subjective Well-Being Among Adolescents. International Journal of Research Studies in Psychology, 3(3).

Ardichvili, A. (2011). "Invited Reaction: Meta-Analysis of The Impact of Psychological Capital on Employee Attitudes, Behaviors, and Performance”. Human Resource Development Quarterly, 22, $153-156$.

Bakker, A. B., \& Oerlemans, W. (2011). Subjective well-being in organizations. (Edt: K. Cameron \& G. Spreitzer.), The Oxford handbook of positive organizational scholarship, Oxford University Press. 49, 178-189.

Bolelli, M. (2020). Psikolojik Sermayenin Öznel İyi Oluş Üzerindeki Etkileri: Türkiye'den Bir Araştırma. International Journal Of Management and Administration, 4(8), 245-259.

Chen X, Zeng G, Chang EC and Cheung HY (2019). What are the Potential Predictors of Psychological Capital for Chinese Primary School Teachers? Frontiers in Education, 4(50), 1-8. doi: 10.3389/feduc.2019.00050.

Chiesa, R., Fazi, L., Guglielmi, D., \& Mariani, M. G. (2018). Enhancing Substainability: Psychological Capital, Perceived Employability, and Job Insecurity in Different Work Contract Conditions. Sustainability, 10(7), 2475. 
Costa, S., \& Neves, P. (2017). Job Insecurity and Work Outcomes: The Role of Psychological Contract Breach and Positive Psychological Capital. Work \& Stress, 31(4), 375-394.

Çavuş, M. F., \& Gökçen, A. (2015). Psychological Capital: Definition, Components and Effects. British Journal of Education, Society and Bebavioural Science, 244-255.

Çetin, F. ve Basım, H. N. (2012). Örgütsel Psikolojik Sermaye: Bir Ölçek Uyarlama Çalışması. Amme İdaresi Dergisi, 45(1), 121-137.

Çetin, F., Turgut, H., \& Sözen, H. C. (2015). Öznel İyi Oluşun Yordanmasında Sabit Kişilik Örüntüsü: Psikolojik Sermayenin Aracillk Rolü. Türk Psikoloji Dergisi, 30(76), 68.

Darvishmotevali, M., \& Ali, F. (2020). Job Insecurity, Subjective Well-being and Job Performance: The moderating Role of Psychological Capital. International Journal of Hospitality Management, 87, 102462. https://doi.org/10.1016/j.ijhm.2020.102462.

Diener, E. (2000). Subjective Well-being: The Science of Happiness and a Proposal for a National Index. American Psychologist, 55(1), 34-43. doi:10.1037/0003-066x.55.1.34.

Diener, E., \& Ryan, K. (2009). Subjective Well-Being: A General Overview. South African Journal of Psychology, 39(4), 391-406. doi:10.1177/008124630903900402.

Diener, E., Lucas, R. E., \& Oishi, S. (2002). Subjective Well-being: The Science of Happiness and Life Satisfaction. Handbook of Positive Psychology, 2, 63-73.

Eid, M., \& Larsen, R. J. (Eds.). (2008). The Science of Subjective Well-being. New York, NY: Guilford Press.

Ergün, E. ve Nartgün, Ş. S. (2017). Öğretmen Öznel İyi Oluş Ölçeğinin Türkçeye Uyarlanması: Geçerlik ve Güvenirlik Çalışması. Sakarya University Journal of Education, 7(2), 385-397.

Gupta, D., \& Shukla, P. (2018). Role of Psychological Capital on Subjective Well-Being Among Private Sector Female Employees. Indian Journal of Health \& Wellbeing, 9(5).

Hansen, A., Buitendach, J. H., \& Kanengoni, H. (2015). Psychological capital, subjective well-being, burnout and job satisfaction Amongst Educators in the Umlazi Region in South Africa. SA Journal of Human Resource Management, 13(1). doi:10.4102/sajhrm.v13i1.621.

Holder, M. D. (2012). Happiness in Children: Measurement, Correlates and Enhancement of Positive Subjective Well-Being. Springer Science \& Business Media.

Ibrahim, M., Karollah, B., \& Amir, F. (2019). The Role of Psychological Capital as Mediating the Effect of Job Insecurity on Job Satisfaction: An Investigation at the Banda Aceh Meuraxa Public Hospital. International Journal of Social and Administrative Sciences, 4(2), 297-305.

Ilgaz, D., \& Sayar, G. H. (2018). Pozitif Psikoloji Uygulamaları Eğitiminin Öğretmenlerin Psikolojik Sermaye ve Öznel İyi Oluş Düzeylerine Etkisi. Psikoloji Araştırmalar Sempozynumu, s.63-67.

Lee, Y. L., \& Yang, D. J. (2019). Potential Contributions of Psychological Capital to the Research Filed of Marketing. Frontiers in Psychology, 10, 2111. doi: 10.3389/fpsyg.2019.02111.

Li, B., Ma, H., Guo, Y., Xu, F., Yu, F., \& Zhou, Z. (2014). Positive Psychological Capital: A New Approach to Social Support and Subjective Well-Being. Social Behavior and Personality: An International Journal, 42(1), 135-144. doi:10.2224/sbp.2014.42.1.135

Luthans, F. ve Youssef, C.M. (2004). Human, Social, and Now Positive Psychological Capital Management: Investing in People for Competitive Advantage. Organ Dyn 33(2),143-160.

Luthans, F. (2002). Positive Organizational Behavior: Developing and Managing Psychological Strengths. Acad. Manage. Execut., 16, 57-72. doi: 10.5465/ame.2002.6640181

Luthans, F. (2011). Organizational Behavior: An Evidence-Based Approach. New York: The McGrow-Hill Companies.

Luthans, F., Avey, J. B., Avolio, B. J., Norman, S. M., \& Combs, G. M. (2006). Psychological Capital Development: Toward a Micro-Intervention. Journal of Organizational Behaviour, 27(3), 387-393.

Luthans, F., Avolio, B.J. Avey, J. B. \& Norman, S. M. (2007). Positive Psychological Capital: Measurement and Relationship with Performance and Satisfaction. Personnel Psychology, 60, 541-572.

Luthans, F., Youssef, C. M., \& Avolio, B. J. (2015). Psychological Capital and Beyond. Oxford University Press, USA.

Lyubomirsky, S., King, L., \& Diener, E. (2005). The Benefits of Frequent Positive Affect: Does Happiness Lead To Success? Psychological Bulletin, 131(6), 803-855. 
Maddux, J. E. (2018). Subjective Well-Being and Life Satisfaction: An Introduction to Conceptions, Theories, And Measures. Routledge/Taylor \& Francis Group.

Margitics, F., \& Pauwlik, Z. (2009). Depression, Subjective Well-Being and Individual Aspirations of College Students. Nova Science Publishers, Incorporated.

Moore, Catherine (2020). Subjective Well-Being: Why is it Important and How Can We Measure it. https://positivepsychology.com/subjective-well-being/(Erişim Tarihi: 10.10.2020).

Newman, A., Ucbasaran, D., Zhu, F. E. I., \& Hirst, G. (2014). Psychological Capital: A Review and Synthesis. Journal of Organizational Behavior, 35(S1), 120-138.

Nolzen, N. (2018). The Concept of Psychological Capital: A Comprehensive Review. Management Review Quarterly, 68(3), 237-277. Sons.

Pryce-Jones, J. (2010). Happiness at Work: Maximizing Your Psychological Capital for Success. John Wiley \&

Renshaw, T. L., Long, A. C. ve Cook, C. R. (2015). Assessing Teachers' Positive Psychological Functioning At Work: Development and Validation of the Teacher Subjective Wellbeing Questionnaire. School Psychology Quarterly, 30(2), 289-306.

Singhal, H., \& Rastogi, R. (2018). Psychological Capital and Career Commitment: the Mediating Effect of Subjective Well-being. Management Decision, 56(2), 458-473. doi:10.1108/md.

Yaşlıŏ̆lu, M. M. (2017). Sosyal Bilimlerde Faktör Analizi ve Geçerlilik: Keşfedici ve Doğrulayıc1 Faktör Analizlerinin Kullanılması. Istanbul Üniversitesi Issletme Fakültesi Dergisi, 46, 74-85.

Zhen, Y., \& Mansor, Z. D. (2020). A Review On The Relationship Between Psychological Capital And Job Attitudes With The Mediating Effect Of Work Engagement in Hotel Industry. Journal of Critical Reviews, 7(2), 591-600. 